\title{
Assessing Students' Conceptual Understanding in Science: An Introduction about a National Project in Taiwan
}

\author{
Mei-Hung Chiu ${ }^{1}$ \\ Chorng-Jee Guo ${ }^{2}$ \\ David F Treagust ${ }^{3}$ \\ ${ }^{1}$ Graduate Institute of Science Education \\ National Taiwan Normal University, Taipei, Taiwan; e-mail: mhchiu@ntnu.edu.tw \\ ${ }^{2}$ Department of Natural Science Education, National Taitung University; \\ Taitung, Taiwan; e-mail: cjguo@nttu.edu.tw \\ ${ }^{3}$ Science and Mathematics Education Centre, Curtin University of Technology, Perth, \\ Australia; e-mail: D.F.Treagust@curtin.edu.au
}

\begin{abstract}
In this article, we discuss several aspects of the national project, the National Science Concept Learning Study (NSCLS), designed to assess elementary, middle and secondary students' conceptual understanding in science. After a short introduction to provide some history of the project, we describe the processes used in the integrative study, the participants in the research, the involvement of about 30 senior researchers and 80 research assistants, and the findings from the national data. Although the results of Taiwanese students' conceptions in science are similar to those of western countries, some aspects of our students' performance are unique to Taiwanese culture and language. This article concludes with some educational implications from the research findings.
\end{abstract}

\section{Where we started}

For more than 30 years, research has looked into students’ conceptions of science 
and a growing interest in a conceptual change in learning and teaching science. Researchers began to identify which concepts in science were difficult for students to learn and then considered which perspectives researchers and science educators could offer to make the concepts more explicit; which strategies we could apply to challenge the imperfect, deficient, incomplete, underdeveloped mental representations and to overcome the difficulties of learning science; and which learning theories could explain the flaws, gaps, or omissions of knowledge held by students. Such questions steered much investigation of scientific concepts for different ages, cultures, and genders over time. The common consensus of the research findings indicated that students have similar conceptions about science, regardless of gender and age.

Many different terms (i.e., misconceptions, alternative conceptions, or children’s science; personal models of reality) were used to describe students' conceptions that differ from the well-recognized concepts in science community. In this Special Issue, we respect each author's personal preference and arguments about the use of the terminology in their papers. Because it was not our intention to discuss what the best word is to describe students' idea about science in this issue. If so, we might need to explain what we meant by a concept and conceptions (diSessa \& Sherin, 1998; White, 1994) and then specify it in a discipline. Even so, we still face a problem of various definitions about a concept in a single discipline. What we intended to do was to capture what our students thought in their mind via a specific method, two-tier diagnostic instrument (proposed by Treagust, 1988, 1995), of data collection. Therefore, we left the debate of reaching a consensus of the terminology behind and let the readers make their own decision and capture the merit of each article in this Special Issue.

So why should we spend more time, effort, and human and financial resources to continue to conduct this type of research? Is our research in science education out of 
date? Or did we perceive opportunities for and challenges to society that necessitated action in research? To what extent could we put the theory of science education into practice? Upon what basis could textbook writers develop and design science curricula? Also, are Taiwanese students' conceptions different from those of students in other countries? Could we generate learning theories that reflect characteristics of our culture? Taiwanese researchers have been alert to (or aware of) and active to the mainstream of studies in science education, publishing papers in international journals and attending international conferences: Are we on track with what we aimed to accomplish?

With these questions in mind, an integrative research effort was undertaken to construct a databank of students' conceptions in science and develop learning and instructional strategies for encouraging students' conceptual change. The research focused on investigating resources or attributes of alternative conceptions, or misconceptions, and then building theories for science learning. This national research mission, which required a rigorous methodological format and timeline, could not be completed without strong arguments and much enthusiasm.

\section{What we aim for}

At first glance, this research did not attract any researchers. As stated earlier, investigating students' conceptions is no longer considered new, innovative, or inspiring enough to warrant the effort. However, one argument proved to be persuasive enough to recruit researchers with science and science education backgrounds from universities to participate in the research: Apart from TIMSS (whose purpose is different from the effort discussed here), there is no national databank of students' science conceptions in Taiwan (nor in the world), and no nation has collected data using the design described in this article and other articles in this 
special issue. The work would contribute to the literature of our understanding of students' conceptions from elementary schools to secondary schools at a global level.

Therefore, the purpose of the integrative research was:

1. To construct a databank of students' understanding of science.

2. To understand patterns of students' conceptions of science.

3. To involve in-service science teachers in research.

4. To investigate the resources and causes of students' science learning.

5. To generate cultural characteristics of learning theory-if one exists.

In order to achieve these goals, we held a number of workshops, seminars, conferences, meetings, and discussions as well as issued semi-annual reports to the National Science Council to brainstorm, communicate with each other, update learning theories, share insightful ideas, and make decisions for the entire group (see Appendix). The national project was called the National Science Concept Learning Study (NSCLS).

\section{Who was involved in the NSCLS?}

Professors and researchers in science education and the science domain from universities (mainly universities with a long history of research and teaching experience in elementary and secondary education) were invited to submit proposals to the special project on the area of learning science. The researchers all had physics, chemistry, or biology backgrounds as well as science education experience. During the development process, external experts also were invited to serve as reviewers to check the validity of the instruments.

We also recruited experienced teachers to participate in the study for their professional development. This decision was influential. At the end of the 1990s, the Taiwan government initiated a masters program in education (MA or MS) for 
in-service teachers. These teachers attended universities to learn about theories and practices of science teaching and learning to improve their instruction in school. By then, widespread recognition of action research was considered a means of recruiting these people—school science teachers and masters students in science education—as research assistants in the projects. In the preparatory phase, the work focused on training in-service teachers to be involved in the project, to educate teachers to understand and develop diagnostic test items, to direct in-service teachers how to interview students, and to practice the skills of design and interviewing prior to the outset of the task.

As for the interviews, questions were raised about what to ask and how to probe students' conceptions in science. The in-service teachers learned about science learning by studying the literature of students' conceptions in science, designing diagnostic test items, and interviewing their students in schools. Students' informal and intuitive ideas were revealed to teachers who rarely have access to their students’ ideas via probing. Nevertheless, their experience and knowledge about teaching contributed to the interview task.

The impact of having in-service teachers conduct research with students was not measurable by any statistical methods. Teachers play a central role in introducing the scientific view. Discourse between students and teachers are important for conceptual change to take place (Hewson, Beeth, \& Thorley, 1998). Without knowing about students' existing understanding of science, which private theories they hold, and the influences of their naïve thinking on their understanding of science, how can science teachers teach effectively and meaningfully to learners?

\section{What we found}

The 10 papers in this Special Issue-from the nationwide assessments of different 
science subjects-address the central questions described in the previous section. The structure of this special issue has three sections described as follows: The first section includes the introduction which describes the background (Chiu, Guo, \& Treagust) an overview placing the Taiwanese research in an international context (Treagust \& Chandrasegaran) and details of methodology for the entire research (Tam \& Li). The second section comprises three articles from principal investigators in each science domain that provide an overview of studies completed in each domain chemistry (Chiu), physics (Chang, Chen, Guo, and Chen), and biology (Wang, Wu, and Huang). The third section comprises four individual articles showing particular interesting findings from each sub-project.

More specifically for the first section, Chiu et al. start with an introduction of background and major findings of this integrative research. The preparation for this research took almost a year before it was sponsored and carried out. Many meetings, workshops, and brainstorming discussions with local and foreign scholars took place to avoid errors in methodology and consider theories of learning and then to determine the direction and central methods for designing diagnostic items and collecting data. Treagust and Chandrasegaran provide an international perspective on the research process and the research findings from the NSCLS. Tam and Li explain the details of techniques that all the studies used in analyzing the national data. They also discuss how the sampling and data collection process for the NSCLS was conducted: A multistage stratified cluster sampling design was adopted for the NSCLS and carried out across the whole nation. Well-designed selections of samples allowed our data to capture students' conceptions of science at different ages and in different regions of Taiwan.

In the second section, Chiu's paper describes the trajectories of students' chemical knowledge and language effect from elementary, junior high, and senior 
high schools. In particular, the discussion addresses the ontological nature of the investigated chemical concepts, which leads to directions for designing strategies for conceptual change learning in the follow-up research. Chang, Chen, Guo, and Chen examine students' conceptions in selected topics in physics, such as force and motion, current in the electric circuit, vision, image formed by lenses and mirrors, sound, the torque and rotational motion, and water pressure. Some ideas were relatively easy (e.g., sound and water pressure) for students to conceptualise while learning complicated concepts in physics, whereas other ideas proved difficult (image formed by lenses and mirrors, force and motion) for students trying to develop a coherent and correct repertoire for linking conceptions together. Again, they found developmental growth in science learning, which is consistent with other studies. Wang, $\mathrm{Wu}$, and Huang analyse the relations between students' background information and performance on the diagnostic test of biological concepts. This research identified environmental aspects, such as urban-rural locations and various types of media, as factors in students' biological learning. Self-efficacy was also an indicator for students' learning in biology and there was no significant difference between male and female students, which we considered to be an important indicator for Taiwanese biology education.

In the third section, Tsai, Chen, Chou, and Lain found that Taiwanese students did not show a high percentage of alternative conceptions of electrical circuits, unlike research completed in western countries. The difficulty of learning about electricity was evident in Lee's findings of students' conceptions of electricity which are consistent with studies conducted in western countries. In Kao's article that investigated aboriginal students' conception of science, she found that students' understanding is strongly related to their personal experiences in a particular culture. Each culture creates a different flavor for constructing ideas pointing to the 
differences of students' prior and existing knowledge as well as their experiences. This Special Issue concludes with an article by Yen, Yao, and Mintzes that is the only one not to use the national data from the project. Their research investigated students' conceptions of animal classifications that illustrate student learning in the Taiwanese culture and the importance of Chinese characters that carry semantic meaning,

\section{What difficulties and challenges we confronted}

After four years of work on this task, we have accomplished some achievements as well as confronted some problems that posed significant challenges. On the one hand, we acquired valuable experience and expertise in conducting a large-scale study with a structural framework and research methodology and constructed a national databank of students' conceptions in physics, chemistry, and biology as reference for science education researchers, curriculum designers, and policy makers. This macro-level approach allowed us to make inferences about the impact of our science education system and predictions about which student learning problems needed more attention. On the other hand, this macro-level approach did not provide us with detailed information about how students generate their representations of conceptions in relation to the physical world, scientific symbols, scientific models, and terminologies for learning science. The limitation of the multiple-choice design in the two-tier diagnostic instrument precludes us from acquiring a better understanding of individual differences and the coherence of students' mental representations of the knowledge. For instance, there is a diversity of views concerning the coherence versus fragmentation in the development of concept (Ioannides \& Vosniadou, 2002; diSessa, Gillespie, \& Esterly, 2004; Thagard, 1992, 2000). Ioannides \& Vosniadou (2002) claimed that students tended to synthesize instructional materials of force concepts to internally consistent mental models, while diSessa et al. (2004) argued that students' 
ideas are not random and chaotic; but neither are they simply described and strongly systematic. Therefore, the lack of micro-level analysis weakens the explanatory power of our data but also provides opportunities for other researchers to build upon.

\section{What learning theories and methodology are developed and generated:}

\section{From traditional to innovative}

Theory. As stated earlier, the research into students' conceptions is not a new area in science learning. However, despite the similarity of purpose, our use of a completely different methodology and theories points us into different directions, conclusions, and implications. For instance, for the past decades, we have moved from behaviorism to constructivism, from Piaget and Bruner to cognitive scientists, from unitary representation to multiple representations, from a single explanation framework to multiple frameworks. These changes make it possible to appreciate further each individual's unique approach to constructing a "private universe" in learning science. In the data presented in this Special Issue, we share some similarities and commonalities of our students' characteristics of understanding in science to other countries' students, as well as show differences and specialties attributed to our students' learning that are a function of our culture and language. However, we did not intend to narrow down the findings and implications for our local use. On the contrary, based on our experiences, we try to encourage more studies like ours to be carried out and to include various perspectives for investigation.

Duit and Treagust (2003) suggest a multiple framework that attributes learning outcomes to epistemological, ontological, affective, modeling, and scientific literacy perspectives. This framework, based on the research in science learning over the past three decades, pinpoints the complex and intertwined context of learning that prevents students from conceptualizing abstract and anti-intuitive scientific ideas. 
Although the research reported in this article does not address the issues of conceptual change (such as theories, strategies, implementation, etc.), these issues are important. For instance, Chi and her colleagues' $(1994,2005)$ theory of conceptual change is the process of shifting concepts across ontological boundaries (re-assignment or conceptual shifting process), and the re-conceptualisation (shifts within ontological categories), is better to be described as conceptual reorganisation but not ontological shifts. The challenge of learning science is mainly the fact that students may "lack awareness of when they need to shift and may lack an alternative category to shift into” (Chi \& Roscoe, 2002, p.18). The other theory was Vosniadou's (1994, 2002) framework theory that attempted to explain how young children’s conceptual systems formed to interpret their observations about the physical world on the basis of individuals' ontology and epistemology, providing some explanatory coherence. diSessa's (2002) knowledge-in-pieces view of conceptual change provide a completely different perspective/view of conceptual change that explains how one constructs one's mental representation of complex system by involving a large number of diverse kinds of conceptual elements or fragments of knowledge. All these learning theories provide profound and insightful framework for us to uncover several unsolved puzzles in our understanding of students' learning in science and might also provide thorough explanations for our findings in this issue.

This integrative research used in the NSCLS establishes a good base for conducting conceptual-change-approach studies in the future. We believe that without representative data that reflect students' understanding of science, it is impossible to develop appropriate learning and teaching strategies or theories for promoting conceptual change in science. Any new approaches to teaching and/or curriculum development should take into account what research has found about students' knowledge and conceptual understanding during learning and then be transformed 
into a teaching agenda. It is beyond dispute that making a meaningful and profound link between learning and teaching is an essential task. This view is consistent with what Meheut and Psillos (2004) and Meheut (2004) proposed with regards to a teaching-learning sequence (TLS) model that includes a gradual research-based evolutionary process aiming at interlacing the scientific and the student perspectives. A related approach, which appears not to have been pursued by the international science education community, is the notion of educational reconstruction (Kattmann, Duit, Gropengießer, \& Komorek, 1995, 1997; Komorek \& Duit, 2004) which comprises three components - an analysis of content structure, empirical investigations of student's understanding of science content and the construction of instructional modules to address the issues identified. This notion is essentially an integrated constructivist approach.

What we are proposing here is that without a well-planned framework for a large-scale research project, it is difficult to generate valid and valuable data for a country’s science education system. Without empirical evidence from research, science curricula, as well as teaching and learning strategies suggested by the education system, might lead our science teaching and learning away from astray.

Methodology. For decades, we have used paper and pencil multiple-choice test items for assessing students' performance because they are convenient and time-efficient technique to evaluate students' outcomes in learning. In addition, other techniques for probing students' understanding in science are discussed and used in science education research for all levels of education and of all subjects. These techniques provide a wide range of practical methods such as concept mapping, prediction-observation-explanation, interviews-about-instances and interviews-about -events, and concepts, drawing, fortune lines, relational diagrams, word association, and question production (White \& Gunstone, 1992). Mintzes, Wandersee, and Novak 
(1999) also recognise some powerful assessment tools for investigating and reinforce meaningful learning (such as concept maps, V diagrams, portfolios, dialogue-as-data, observation rubrics, SemNet software, and writing) and discuss the limitations of the tools used in the practice.

The studies presented in this volume use a two-tier diagnostic instrument (Treagust, 1988, 1995) to examine students’ understanding of scientific knowledge. Although the technique simply adds one more tier into the test item, as stated above, one small change (in terms of methodology or theory) makes a big difference. This technique has evolved from the traditional multiple-choice method to a profound one to identify and analyse students' mental representations. We could move even one step further, as stated in Chiu's article (in this volume), namely, to overcome the limitations of items in the second tier, we could have a computerized test bank that offers more choices for students, locating more precisely students' understanding of the complex system of science and the interwoven network structure owned by the students. In addition, in a follow-up study, we could continue to collect these data periodically and include studies on topics within the earth science curricula as well as other concepts in physics, chemistry, and biology that have not been previously investigated.

\section{Implications for instruction in science}

Similar to results obtained about students in other countries, the National Science Concept Learning Study shows that students in Taiwan hold misconceptions or alternative conceptions about a number of key concepts in biology, chemistry, and

physics. Taiwanese students, as well, are found to come to school with pre-held ideas about natural events and objects, along with misconceptions about certain science 
concepts-even after formal school instruction. From the results obtained in the NSCL study, there are several important implications for science instruction.

Many science teachers in Taiwan, and their students alike, tend to focus science instruction and testing on memorizing facts, rules, and formulae. Concerned science teachers should be able to realise from the results of this study, that even students who receive competent science instruction can hold misconceptions or alternative conceptions. The development of the two-tier diagnostic test items in this study can also serve as examples that teachers can use to probe students' conceptions, both prior to and after instruction. However, realising the existence of students' misconceptions and knowing the ways to find them out is only the first step toward the desirable instructional goal of students having better conceptual and meaningful understanding of major scientific concepts.

Research efforts to improve science teaching and learning based on the so-called “conceptual change model” (Stepans, 2003) have been carried out during the past few decades, both in Taiwan and the rest of the world. It is now widely known that conceptual changes do not come easily; special efforts, strategies, and time are needed. Therefore, it might be wise for science curriculum frameworks, textbooks, and science teachers to emphasize a minimum number of core concepts and to deal with them in greater depth. Hopefully, students will have opportunities to learn these core concepts correctly, deeply and meaningfully. Of course, both pre-service and in-service science teachers would need to be informed of students' potential misconceptions and become versatile in using conceptual-change instructional strategies in science classrooms. The NSCL study also has identified some of the causes for students' misconceptions, including those associated with the structure and meaning of Chinese words used in textbooks. It is highly desirable that 
science textbook writers and science teachers are aware of the common causes for students' misconceptions.

\section{Reflections on how to put theory into practice}

Much of the current theoretical understanding of how students learn is summarized in a book published in the USA by the National Research Council (2000). It points out that a fundamental tenet of modern learning theory is that different kinds of learning goals require different approaches to instruction; new goals for education require changes in opportunities to learn. The design of the learning environment is linked to issues that are especially important in the processes of learning, transfer, and competent performance. Those processes, in turn, are affected by the degree to which learning environments are student-centered, knowledge-centered, assessment-centered, and community-centered (National Research Council, 2000). Based on research findings and similar instructional principles as delineated in the National Research Council’s book (2000), various instructional strategies aimed at facilitating students' conceptual change have been developed in recent years (Mintzes, Wandersee, \& Novak, 1998; Stepans, 2003; Coll, France, \& Taylor, 2005; Slotta \& Chi, 2006; Vosniadou, Skopeliti, \& Ikospentaki, 2005).

In principle, science educators to date are in a much better position to prepare science teachers than they were a few decades ago. In practice, however, the task to achieve better science teaching and learning remains a difficult and challenging one. There are many variables involved in the contexts, inputs, processes, and products of science instruction, and the relationships between these variables are complex and largely unknown. Much uncertainty still exists about how to prepare effective science teachers, to help them develop professionally, and to ensure that students reach a conceptual understanding of important science concepts and other desirable learning 
outcomes in science. Further research and more concerted efforts among policy makers, science education researchers, and science teachers are needed (Symington \& Tytler, 2004).

\section{Acknowledgement}

The first two authors would like to thank sincerely the Taiwanese National Science Council for support of the integrative projects (NSC 89-2511-S-003-157-, NSC 90-2511-S-003-105-, NSC 91-2522-S-003-022, NSC 92-2511-S-003-060 for the first author “chemistry group coordinator”; NSC 89-2511-S-018-044, NSC 90-2511-S-143-009, NSC 91-2522-S-143-009, NSC 92-2511-S-143-007 for the second author "Project leader”) and Professor David Treagust for continuous support in helping bring the completed research together in this special issue .

We wish to acknowledge the diligence and editorial expertise of Dr Chi-yan Tsui and Dr A L Chandrasegan who read and edited the final submitted manuscripts.

\section{References}

Chi, M.T.H. (2005). Common sense conceptions of emergent processes: Why some misconceptions are robust. Journal of the Learning Sciences, 14, 161-199.

Chi, M.T.H. \& Roscoe, R.D. (2002). The processes and challenges of conceptual change. In M. Limon and L. Mason (Eds.), Reconsidering conceptual change: Issues in theory and practice. The Netherlands: Kluwer Academic Publishers, $3-27$.

Chi, M. T. H., Slotta, J. D. and de Leeuw, N. (1994). From things to processes: A theory of conceptual change for learning science concepts. Learning and Instruction, 4, 27-43. 
Coll, R. K., France, B., \& Taylor, I. (2005). The role of models/and analogies in science education: Implications from research. International Journal of Science Education, 27(2), 183-198.

diSessa, A. A. (2002). Why “conceptual ecology” is a good idea, in M. Limon \& L. Mason (Eds.), Reconsidering conceptual change. Issues in theory and practice. Netherlands: Kluwer Academic Publishers, 29-60.

diSessa, A. A., \& Sherin, B. L. (1998). What changes in conceptual change? International Journal of Science Education, 20(10), 1155-1191.

diSessa, A. A., Gillespie, N. M., \& Esterly, J. B. (2004). Coherence versus fragmentation in the development of the concept of force, Cognitive Science, 28, 843-900.

Duit, R. \& Komorek, M. (2004). The teaching experiment as a powerful method to develop and evaluate teaching and learning sequences in the domain of non-linear systems, International Journal of Science Education, 26(5), 619-633

Duit, R., \& Treagust, D. (2003). Conceptual change: A powerful framework for improving science teaching and learning. International Journal of Science Education, 25(6), 671-688.

Hewson, P. W., Beeth, M. E., \& Thorley, N. R. (1998). Teaching for conceptual change. In B. J. Fraser and K. G. Tobin (Eds.), International handbook of science education. London: Kluwer Academic Publishers, 199-218.

Ioannides , C. \& Vosniadou, S. (2002). The changing meanings of force. Cognitive Science Quarterly, 2, 5-61.

Kattmann, U., Duit,R., H Gropengießer,H., \& M Komorek, M. (1995). Educational reconstruction - bringing together issues of scientific clarification and students' conceptions Paper presented at the annual meeting of the National Association for Research on Science Teaching, St Louis, Mo, April. 
Kattmann, U., Duit,R., H Gropengießer,H., \& M Komorek, M. (1997). Das Modell der Didaktischen Rekonstruktion-Ein Rahmen für naturwissenschaftsdidaktische Forschung (The model of educational reconstruction: A model for science education research and development). Zeitschrift für Didaktik der Naturwissenschaften, 3(3), 3-18.

National Research Council. (2000). How people learn: Brain, mind, experience, and school. In J. D. Bransford, A. L. Brown, \& R. R. Cocking (Eds.), Committee on developments in the science of learning. Washington, D.C.: National Academy Press.

Meheut, M. (2004a). Teaching-learning sequences: aims and tools for science education research, International Journal of Science Education, 26(5), 515-535.

Meheut, M. (2004b). Designing and validating two teaching-learning sequences about particle models, International Journal of Science Education, 26(5), 605-618.

Mintzes, J. J., Wandersee, J. H., \& Novak, J. D. (eds.) (1998). Teaching science for understanding: A humanistic constructivist view. San Diego: Academic Press.

Mintzes, J. J., Wandersee, J. H., \& Novak, J. D. (eds.) (1999). Assessing science understanding: A human constructivist view. San Diego: Academic Press.

Slotta, J. D. \& Chi, M.T.H. (2006). The impact of ontology training on conceptual change: Helping students understand the challenging topics in science. Cognition and Instruction, 24(4).

Stepans, J. (2003). Targeting students' science misconceptions: Physical science concepts using the conceptual change model. Tampa, FL: Showboard, Inc.

Symington, D. \& Tytler, R. (2004). Community leaders' views of the purposes of 
science in the compulsory years of schooling, International Journal of Science Education, 26(11), 1403-1418.

Thagard, P. (1992). Conceptual revolutions. Princeton, NJ: Princeton University Press.

Thagard, P. (2000). Coherence in thought and action. Cambridge, MA: MIT Press.

Treagust, D. (1988). Development and use of diagnostic test to evaluate students' misconceptions in science. International Journal of Science Education, 10(2), 159-169.

Treagust, D. F. (1995). Diagnostic assessment of students’ science knowledge. In Glynn, S. M. \& Duit, R. (Eds.), Learning science in the schools: Research reforming practice. Mahwah, NJ: Erlbaum, 327-346.

Vosniadou, S. (1994). Capturing and modeling the process of conceptual change. Learning and Instruction, 4, 45-69.

Vosniadou, S. (2002) On the nature of naïve physics. In M. Limon \& L. Mason (Eds.), Reconsidering conceptual change. Issues in theory and practice,. Netherlands: Kluwer Academic Publishers, 61-76.

Vosniadou, S., Skopeliti, I. \& Ikospentaki, K. (2005). Reconsidering the role of artifacts in reasoning: children's understanding of the globe as a model of the Earth. Learning and Instruction, 15, 333-351.

White, R. T. (1994). Commentary: Conceptual and conceptional change. [special issue]. Learning and Instruction, 4, 117-121.

White, R. T. \& Gunstone, R. (1992). Probing Understanding. PA: The Falmer Press. 


\section{Appendix}

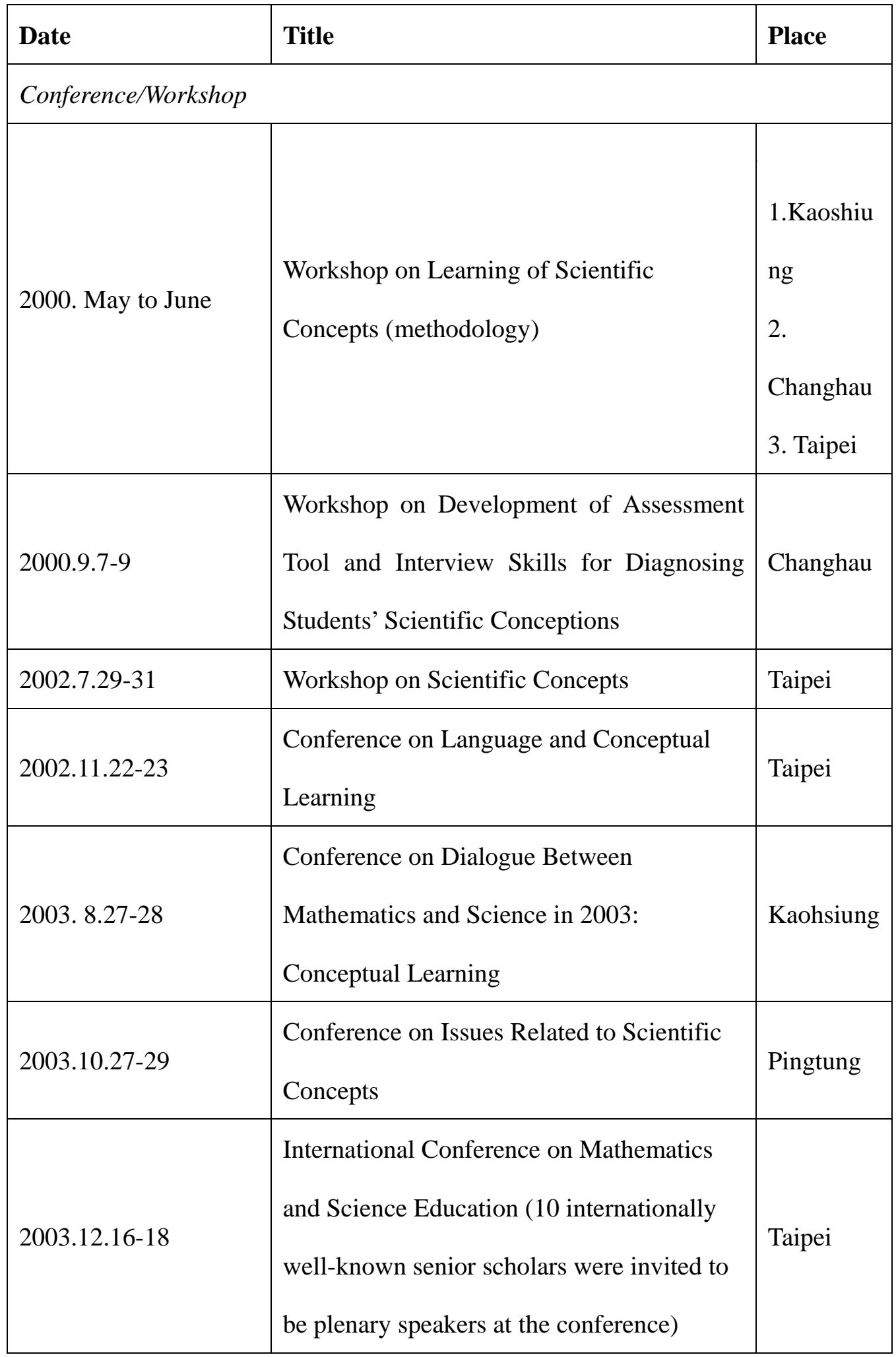




\begin{tabular}{|l|l|l|}
\hline 2006. 3.18-19 & \multicolumn{1}{|l|}{$\begin{array}{l}\text { Follow-up Conference on Promoting } \\
\text { Scientific Concepts Understanding }\end{array}$} & Changhua \\
\hline Annual Report Meeting & $\begin{array}{l}\text { Annual oral report of integrative projects in } \\
\text { science concepts sponsored by National } \\
\text { Science Council, Taiwan, in 2001 }\end{array}$ & Taitung \\
\hline $2003.2 .12-13$ & $\begin{array}{l}\text { Annual oral report of projects in science } \\
\text { concepts sponsored by National Science } \\
\text { Council, Taiwan, in 2002 }\end{array}$ & Taipei \\
\hline
\end{tabular}

* More than 50 steering meetings were held to make decisions about research directions and conferences for the researchers involved in the integrative projects. The core principle investigators, as well as a well-known international scholar who provided insights to our research, made these decisions. 